Journal of the Textile Institute Proceedings and Abstracts

\title{
YORKSHIRE SECTION: Meeting at Bradford, 3rd March, 1921. Mr. George Garnett in the Chair. PRODUCTION OF WOOLLEN GOODS IN THE PRINCIPAL COMPETING COUNTRIES
}

\section{J. S. M. Ward B.A. and F.R.Econ.S. and F.S.S.}

To cite this article:J. S. M. Ward B.A. and F.R.Econ.S. and F.S.S. (1921) YORKSHIRE SECTION: Meeting at Bradford, 3rd March, 1921. Mr. George Garnett in the Chair. PRODUCTION OF WOOLLEN GOODS IN THE PRINCIPAL COMPETING COUNTRIES, Journal of the Textile Institute Proceedings and Abstracts, 12:4, 103-109, DOI: $10.1080 / 00405002108631019$

To link to this article: http://dx.doi.org/10.1080/00405002108631019

曲 Published online: 25 Nov 2008.

Submit your article to this journal $₫$

Џ Article views: 4

Q View related articles ¿ 
and the oil added in the course of combing remained mainly on the surface. In the boiling process, it would be removed from the fibre and deposited on the hanks. With a different character of wool, where the same quantity of oil was used, this did not-occur. Was it possible to detect the latent capacity of oil to develop the difficulty of polymerisation? Was it something that could be seen in a bottle or was it something that remained soluble?

The LECTURER pointed out that he had especially referred to the chroming of tops in hank form. The top portion was hard and the bottom portion was satisfactory. If the chroming was done in ball form there was not the same difficulty. It was possible by chemical tests to detect the liability of an oil to develop polymerisation.

Major BLISS (Leeds) heartily endorsed what Dr. Lloyd had said with regard to trouble arising from the use of conditioning agents on yarn. The practice ought to be abolished and the material paid for on the basis of dry weight, and not conditioned weight.

Subsequently, in moving a vote of thanks to the lecturer, Major Bliss congratulated the Textile Institute and Dr. Lloyd on the practical nature of the lecture. The wool textile industry needed far more lectures on scientific lines.

Mr. RAPER, in seconding the motion, endorsed what Major Bliss had said, and added that he would like to hear a lecture telling them what oils to use and not merely the oils they ought not to use.

\section{YORKSHIRE SECTION.}

Meeting at Bradford, 3rd March, I92I. Mr. George Garnitr in the Chair.

\section{PRODUCTION OF WOOLLEN GOODS IN THE PRINCIPAL COMPETING COUNTRIES}

(With particular reference to Labour Conditions and the Rate of Exchange).

By J. S. M. WARD, B.A., F.R.Econ.S., F.S.S.

In the above-named paper, the author dealt most exhaustively with the subject, pointing out at the outset that the fact that four-fifths of our food supplies are bought by the exportation of goods is often overiooked in political circles. In 1920 , the total exports from the United Kingdom represented $£ \mathrm{I}, 557,974,984$; the total in respect of articles wholly or mainly manufactured was $£_{1}, 120,731,798$, and of this sum textile exports contributed $£ 635,774,789$. The present industrial crisis might be usefully considered with a view to ascertaining how far it might be possible for wool manufacturers of this country to alleviate the difficulties of the situation.

A good deal has been said about the desirability of stabilising the rates of exchange. What is required is the restoration of the rates of exchange to something approximating to pre-war parities. Often enough, the question of exchange is confounded with that of cost of production, and some light on the conditions in the woollen industry in the various countries may be useful.
After careful examination, it may be said, roughly, that our costs of production are above those of the average world costs, and one of the principal causes of this has been our taxation under E.P.D. This tax led to enhanced selling price both to home and foreign consumer, with the result that the price became more than could be paid. Even now that E.P.D. has gone, we find ourselves heirs to the spirit of carelessness and extravagance which it promoted. It is one thing to refuse to grant an unnecessary expenditure or an increase in wages or salaries; it is quite another and more difficult thing to withdraw such concessions after they have been made and experienced. Again, the burden of income-tax is most crushing in relation to industry, reducing as it does the home consumption. A reduction of this tax will only become possible if the Government is compelled by steady pressure of popular opinion to reduce its expenditure. The mere psychological effect of even a small reduction in the income-tax would be so valuable that it must not be thought that even sixpence off the income-tax would be negligible. There must be considerable reductions in cost of production, cessation of strikes and trade disputes, and economical methods applied if trade is to recover effectively. Reduction in the cost of our goods would tend to improve the rates of exchange of our principal customers, who, having to pay less for our goods, would find that their depreciated units would rise. Consider the position of affairs in competing countries.

It is often said that a certain country is able to sell its goods in England at a lower price than we ourselves can owing to the depreciated rate of exchange. but like many other sweeping statements this one is only partially true. Too much stress is sometimes laid on depreciated rate of exchange, and not enough on the difference in cost of production. Take, for example, the case of Germany. It is commonly pointed out that an article which costs 245 marks in Germany only costs 245 pence when sold in England. What we require to find out, however, is how much 245 marks are worth in Germany itself. In other words, one of the first things to be understood is how far the cost of living in Germany has risen in proportion to the fall in the external value of the mark. It is clear that if the mark has fallen to one-twelfth of its value the German has to pay twelve times as much in marks for the wool he gets from abroad as he did in pre-war days, and this fact must be taken into account by his manufacturer before he can fix his selling price. From the tangle of conflicting evidence, it is somewhat difficult to arrive at a definite decision as to production costs in Germany, but, after careful investigation, I am inclined to think that on the average the following represents the true state :-The cost of production, taking one thing with another, has risen about twelve-fold, the mark has depreciated to one-twelfth of its value, and the net result is that Germany is producing at abont the pre-war cost. This must be compared with the cost in England, which is two-and-a-half times as great as in pre-war days. It would thus appear that Germany has a distinct advantage in cost of production. Observe that this is not simply a question of rate of exchange, but is the net result 
arising from the fall in value of the mark balancing the nominal rise in cost of production. In the case of an industry obtaining its raw materials mainly from within in Germany, the cost of production is probably lower than pre-war cost when translated into the currency of Great Britain; but, where the industry depends mainly or solely on imports of raw materials from abroad, and such raw materials form a large part of the costs, it is probable that production cannot be effected at pre-war rates. This is a serious enough matter, but it may be as well to point out that artificial methods of checking the rate of exchange are not the most satisfactory way of meeting such competition. I do not propose to allow myself to be drawn into the tariff controversy, but would merely point out that what is true of Germany is also true of many other countries, and, in a world competition for trade, though you might debar German goods from coming into England, that would do little good if neutral markets remained available, particularly when considering a large export trade such as the wool trade of Great Britain. In my opinion, the cessation of inflation in Germany, which must come sooner or later, will mean that the cost of production in Germany will rise to an apprecioble extent. The period of transition, however, is likely to be one fraught with great dangers to the present German Government, for increase in cost of living will mean further rise in wages and possibly industrial conflict.

In no branch of the German industry has the cartel form of organisation been developed so extensively as in the textile industry, and the Berlin Year Book of Trade and Industry mentions 55 textile cartels in I9I3. This, despite the fact that there are few large industries which offer greater obstacles to cartelisation than most branches of the German spinning and weaving industries. These industries consist of a vast number of small and medium-sized plants producing a great diversity in qualities and grades of products with constantly changing styles and almost entirely dependent upon foreign markets for raw products, thus rendering it difficult to establish uniform standards and so combine the conflicting textile interests into one cartel. As a result of this, the German textile industry in pre-war days was largely in the hands of middlemen and dealers, and, whereas in other industries the dealers in Germany were controlled by the manufacturers, the opposite was the case in the textile industry. This absence of cohesion between the producers and the dealers has led to repeated conflicts, but the very difficulties which beset the German textile industry have compelled them to form a closer organisation, and in consequence numerous strong bodies were formed, both trade associations for promoting the general interests in a general way, and also cartels for producers and dealers. In addition to these trade organisations, there are a large number of cartels which regulate terms, conditions of sale, and prices. This is one of the most significant developments of the German textile industry, syndicates or common selling agencies being comparatively rare in pre-war days. During and since the war, the tendency has been towards more and more central- isation and organisation in the textile industries, and such information as is available proves that many associations are being intèrlocked or merged. Whereas before the war the German statistics as to production and exports were remarkably good, to-day they either do not exist or are quite unreliable, and how far this is a result of deliberate policy of concealment or of disorganisation caused by the war or revolution is a matter of opinion. Probably both factors are at work.

When we come to consider the general tendency of the wool trade in America, certain facts are manifest. Firstly, the American rate of exchange being high, she has been able to purchase wool against the world relatively cheaper than we could. She, herself, of course, produces very considerable quantities of wool, and on January Ist, I914, had $49,700,000$ sheep and lambs. The total wool clip of the States for I9I 6 was stated by the National Association of Wool Manufacturers to be $288,490,000$ lbs. greasy, or $130,755,700$ lbs. scoured, worth approximately ro8,000,000 dollars. The most important woolbearing state is Wyoming, with $5 \frac{1}{2}$ million sheep, and 36 million $1 \mathrm{bs}$. of wool, with Montana second with $5 \frac{1}{2}$ million sheep and $33 \frac{1}{2}$ million lbs. of wool. Again, in South America, there are between 60 and 70 million sheep. The exact statistics vary, and, although numbers have been tending to decline, they still refer to one of the most important wool crops of the world. In all these countries, the American would be able to buy easier than we could owing to the apprcciation of his dollar, and he is further helped in many cases by improved facilities of shipping, especially now that the Panama Canal is in existence and that the American marine has been increased. Indeed, the difficulty that America has had to contend with is to find cargoes of goods from the South American ports to the States to fill the ships she sends with manufactured goods to those countries. The war also produced a great development in her textile industry. The big orders for military cloths led to great development in the way of wholesale production, but America at the present time does not appear to have solved the problem of distribution. There seems little doubt that America can supply many of the quality goods which we also turn out. The ready-made trade, probably, is considerably ahead of us, but she has her own difficulties, and these must not be ignored. Her high rate of exchange makes it even more difficult for her to sell to the Continent than it does for us. She has altogether in all her industries fully three million men out of employment. She also has her warehouses full of goods she cannot sell, and is cutting her selling price and disposing of her goods often at a loss. But she has an asset, namely, a huge continental area with over a hundred million people in it, and to these she can sell a large quantity of her goods. Nevertheless, it is interesting to note that the American consumers have been complaining as bitterly of the high cost of cloth in America as have the English, and, strange to say, the German consumers were saying the same thing only a month or two ago about German clothing. In Germany, there had even been a recrudescence of 
substitutes, such as paper textiles, the trade in which collapsed at the time of the armistice, but began to revive last April owing to the high cost of woollen and cotton goods.

After careful investigation, I have come to the conclusion that American prices for export to England are slightly above those of similar goods in England, except where manufacturers are custing heavily to obtain cash. This is after counterbalancing the smaller rise in wholesale prices with the appreciation of the dollar.

Before turning to Japan, I think it would be well to set out certain figures which indicate the true position with regard to these various countries, reducing them to a common denominator as far as possible. It must be understood that these figures can be but an approximation. They are an average, which though true on the average would very often be incorrect on a particular article, or possibly a whole section of a trade, and they represent the average for all trades.

The pre-war price of a certain quantity of goods in the United Kingdom would be say $£_{1} \circ$, and in U.S.A. competing goods would be shipped at 487 dollars, Japanese at 980 yen, French goods at 2,500 francs, Italian at 2,500 lira, and German goods at 2,000 marks. In December, the United States dollar had risen so that froo was only worth 349 dollars, which equals $+39.4 \% ; f_{\text {I IOO }}$ in Japan was worth 712 yen or $+37.6 \%$; while, on the other hand, the franc had depreciated so that our previous $£$ Ioo, formerly equalling $2,500 \mathrm{fr}$, now purchased 5,894 , or in other words the franc had fallen by $-57 \cdot 2 \%$. £Ioo would buy 9,996 Italian lira, which coin had depreciated to $-74.7 \%$; while $£$ roo, which was formerly the equivalent of 2,000 marks would now purchase 25,464 marks, showing a depreciation of $-92 \%$.

Next let us see what a rise in the wholesale prices Index Number was, taking I9I4 as equalling $£$ roo. In England, it had risen to 254 -that is to say $£_{100}$ worth of goods cost $£ 254$; in U.S.A., it had risen to only $19 \mathrm{I}$; in Japan, it had risen to 226 ; in. France to 125 ; in Italy to 733 ; and in Germany to $r, 640$. These, remember, are wholesale prices not retailnot the cost of living, but the increased selling cost of such articles as woollen cloth to the wholesaler. In short, the selling price inside Germany of woollen cloth to the wholesaler was, approximately, $161 / 2$ times what it had been before the war. Now, if we work out these wholesale figures in conjunction with the depreciated rates of exchange, we get the following factors for the present price at which these countries can sell their goods to England:- In Eingland, $£_{254}$ in December purchased what had cost $\mathcal{L}_{100}$ before the war; the United States can sell those goods for 930 dollars, which was equal to $£_{2} 66$; the Japanese could sell them at 2,218 yen or $f_{3} \mathrm{II}$; France would sell them for 10,620 francs (the equivalent that is of $£_{\mathrm{I}} 80$ ) ; Italy for 18,350 lira (or the equivalent of $\left.£_{1} 84\right)$; and Germany for 32,800 marks, which is the equivalent of f.r29. Thus, taking Germany, we shall see that a countervailing duty to balance the depreciated rate of exchange would have had to have been $\mathrm{I}, \mathrm{I} 50 \%$ ad valorem, but a counteracting duty to counteract the fall in the cost of production, as translated into English currency in that month, would have been $97 \%$. In other words, at that time Germany could actually sell at half our production costs.

In studying these figures, one must remember that these, while true, are largely academically true. Thus, in many cases, Germany has not the goods to sell at all. For various reasons-lack of raw materials for example, or depreciation of her plant - she cannot supply sufficient for her own wants, and that this is so is borne out by the trade figures I recently obtained from America showing that we had sold to Germany 33 million pounds worth more goods than we received from her in the period between the ist January, I9I9, and September 3 oth, 1920. In other words, Germany has got to send us 33 million pounds worti of goods before she has wiped out the amount she owes our manufacturers, even if she gets not another thing from us, and the same is true of almost all the Continental countries.

Again, Japan might, theoretically, be able to sell us goods at $\AA_{3} \mathrm{II}$, but this does not take into account the heavy shipment freights which must be paid for bringing these goods from Japan to London, nor does it argue Japan could supply the quality of goods whicin we want; indeed, Japanese goods are cheap grade goods, and the danger from them is not so much that they will threaten our market but rather that the impoverished countries, particularly the Continent, who cannot afford to buy our goods, may buy Japanese goods, which, though cheap and shoddy, are at any rate within their ability to purchase. When a man is practically penniless, he cannot afford to buy an expensive article even though he knows that in the long-run it will pay him better, and that is the position of our customers to-day. Before the war, Japan was making considerable progress in woollen goods productionlargely with a view to export trade. The European war created a boom in the woollen factories owing to large orders from Russia, which, up to 1916 , amounted to nearly 25 million yards. In 1915 , there were about 55,000 woollen spindles, nine-tenths of which belonged to five concerns, whilst worsted spindles were computed at 155,000 , all but an insignificant minority belonging to the mousseline mills. These spindles were estimated to consume $45,000 \mathrm{lbs}$. of tops per 24 hours, or enough to produce roo million yards of mousseline per annum. Combing facilities have increased since 1915 , when there were 52 machine combs.

Whilst most of the hosiery made in Japan appears to be cotton, yet a certain amount of it is mixed with wool. The export, valued at not more than $I / 2$ :villion yen in 1903 , has risen enormously, and by I9I 4 had reached $13,732,000$ yen. 'The export for I919 showed that knitted goods made 17,000 ,000 yen increase. The total value of knitted goods produced in Japan in rgrg is given as $68,500,000$ yen, an increase of $34 \%$ over the previous year.

In woollen tissues, considerable development is recorded. The expurt of cloths and serges from Japan has increased in value from $3,287,000$ yen to $4,993,000$ yen, and in quantity from 953,000 to $\mathrm{I}, 343,000$ yards. Qpinions differ wi:h regard to the quality of goods, but in any case the present cost of production is practically equal to British cost, so that 
on the return to normal conditions in England there should be little to fear from Japanese competition. Despite the large exports, too, the demand for woollen cloth and serges in Japan itself is large and increasing. For I9I8, the import of pure woollen cloths and serges into Japan was valued at over $61 / 4$ million yen, while cloths of mixed wool and cotton were imported to the value of nearly 3 million yen. About $99 \%$ of these fabrics were supplied by Great Britain. It must be remembered, too, that great changes have occurred in Japan in the way of the demands of labour for improved conditions and terms. Generally speaking, present average wages are over roo per cent. in advance of pre-war rates. It is true, of course, that Japanese labour is still considerably cheaper than labour in the West, but the efficiency is much lower by comparison. Under the most favourable conditions, the ratio is not higher than $2-3$, and many writers place it at $1-2$. Considering the tendency to reduced hours, the comparative lack of labour-saving means, and other conditions, it is open to doubt whether the actual cost of production of competitive goods is lower in Japan than in England. In any case, it is submitted that the difference in favour of Japan is not enough to justify the alarmist views which find expression in Great Britain and her Colonies. The bulk of Japan's manufactured articles, however, are still made in the homes, and the hours of working in this case are often long. In general, however, the cost of labour per hour is steadily rising, whilst the average expense for foodstuffs for a Japanese family of five is now about $I, 040$ shillings as against about 300 slinllings at the beginning of the war. In Japan, of course, the cotton industry is preeminently the most important of the new textile industries and to a large extent the wages fixed there influence those of any industry, such as the woollen, which can be compared to it. In 1920 , just as in every other country, Japan has experienced a very severe slump following the great boom.

Regarding the French woollen industry, the occupatiou by the enemy of the Northern part of France led to the development of wool manufacturing in certain other areas and in particular at Lyons. Before the war, the wool industry was a most important one in France, and in rgro the carded woollen yarn produced was at least $S_{2,117,000}$ lbs., of which quantity 20 millions came from Mazamet and $121 / 4$ millions from Roubaix-Turcoing. In the same year, $110,075,000$ lbs. of worsted yarn was produced. Of this, $26 \% / 4$ million lbs. came from Turcoing, 17 millions from Roubaix, and $50 \mathrm{x} / 4$ millions from Fourmies, Cambrai, Amiens, and Aisne. Rheims, which had two large combing works and a number of spinning mills, treated some 20,000 tons of wool in rgog. Marseilles has an important woolcombing industry and is, of course, an important port of entry, particularly for low grade wools, which in I9II amounted to 43,500 tons. Vienne is the centre of the French shoddy trade, and as far back as 1910 it produced 10 $1 / 2$ million lbs. Vienne has the advantage of cheap electric power drawn from the Alps. At Roubaix, in 1912 , there were 267 mills, employing 60,000 persons, one-sixth of whom were employed in wool combing, 410,000 worsted and 85,000 wool spindles. There were also 430,000 cotton spindles. There were 35,000 looms, and the dye works employed ro,ooo people. The devastation wrought during the war, the destruction and loss of nearly half their valuable wool-bearing sheep, and the difficulty of obtaining adequate supplies of wool, all tended to shatter the wool industry in France, and during the last year and a half it has been slowly and painfully recovering. By the ist November, apparently, about $80 \%$ of the factories had been put into working order, but these were only ready in time to find the world's slump liad set in. The latest figures indicate that there is considerable unemployment in the wool industry as in most of the industries in France, which, though it is perhaps not so severe as in England, is nevertheless a sad disappointment to men who have been practically prevented from working till now owing to the damage wrought by the war. On the whole, it appears as if on the average there was a $40 \%$ reduction in full efficiency due to lack of orders. Some firms are running short time and others have dismissed large numbers of workmen, the method employed varying in different localities.

\section{GENERAL CONCLUSION :}

The outstanding feature of the present industrial situation is the absolutely world-wide extent $x$ the trade slump. It is confined to no particular country and to no one industry; it embraces all. Even Germany is suffering from unemployment, and we know what the position is in England. If we go as far away as Cuba, we find that in an entirely different set of industries a similar trade slump is taking place. Japan, America, and British India share with Australia and Central Europe in the universal depression. It is at first sight an extraordinary thing that with the world still short of goods there should be an almost universal cessation of orders. This factor is by no means strange when carefully investigated, nor must it be thought that England alone is suffering from the dumpingso-called-of foreign goods. The same cry comes from practically every country.

I was talking to a representative of the Federation of Swedish Industries only a few days ago and he said that the Swedish industries were suffering severely from the dumping of German goods and that strong pressure had been brought to bear on the Swedish Government to increase the tariffs, but with no result, the Swedish Govermment being afraid of doing anything which would maintain the present cost of living in Sweden. In France, we hear that French factories are having to close because of the importation of German goods which, owing to the depreciated rate of exchange, can be sold there more cheaply. Spain has just doubled her duties, and at the present minute a deputation has gone from the Federation of British Industries to see whether they cannot obtain concessions in favour of British goods; and they are decidedly hopeful that something may be achieved, as they are informed that the reason why Spain has increased her duties is to prevent the dumping of French goods in Spain. America is meditating a 
similar increase in her duties to prevent the dumping of European goods. In short, it would appear as if every country is complaining of dumping and every country is suspected of dumping.

The causes of this strange condition of affairs are mainly the war. The war used up and destroyed not only the current incomes of the various nations but a large amount of their vested capital. These nations further ran into debt and are at the present day impoverished. To imagine that the world can afford all that it wants is obviously a great mistake under such circumstances. If we tcok an individual, we should see this at once. If a man who was not insured had had his house burnt down with most of the goods in it destroyed, had lost important investments and been obliged to borrow money on which to live, we should hardly expect that man to be in a position at once to rebuild his house and furnish it in the old style. This elemental fact was disguised for a short time by the huge inflation of currency and by the fact that while the world as a whole had become poorer certain sections had temporarily benefited. There had been a transference of wealth from many hands into those of a few, but the real wealth which these people manufactured and were paid for was being actively destroyed on the battlefields. A few individuals were able to force up the price of such commodities as existed by ruthless competition and everyone else had to follow suit or go without. Trade being only, in the end, the barter of one set of products for another, it naturally follows that if a large number of our customers are unable to supply certain goods they cannot long purchase goods from us, for they have nothing to give in exchange. It is quite true that the world requires vast quantities of goods, but many of the nations who want them have nothing with which to purchase. Money which would have been used for the purchase of goods, capital which would have been used in business, have alike disappeared in the form of munitions of war. We are left with debts which earn no money, unlike capital invested in a business, but instead are a heavy burden on such industries as do produce wealth.

But if the war was a serious blow to industry, what followed after was probably almost as bad. Every Government in Europe and, in fact, almost every Government in the world, had got into the habit of spending on an extravagant scale, and this has necessitated either a crushing taxation, as in England, or inflation and loans as has happened on the Continent. Crushing taxation reduces the amount the ordinary individual can spend on goods; inflation reduces the value of the currency with which a foreign country can purchase goods from abroad. It likewise increases the burden of living by driving up the cost of living and is, in the end, another form of taxation.

No patent remedy exists. All the proposed schemes which are put forward are, at the best, palliatives. At the worst, they may do serious harm. We must work back to the fundamental principle-that man can have no more than he produces, and that man can only exchange the surplus he has for the surplus which other people produce. While lucky individuals may be able to take advantage of the social conditions in which we live to exist without work, nations cannot, and in the twentieth century it is exceedingly dificult for any man, much less a nation, to work efficiently and economically unless he has considerable capital behind him. War loans and heavy taxation absorb capital which should go into industry. Short hours and slack work reduce the amount of products and therefore increase their cost to the consumer.

I do not think that Bradford has any cause to fear the competition of any foreign country. Her past experience, the ability of her present population, are sufficient to enable her to hold her own in the long-run in any commercial struggle. What she has to fear is the impoverishment of the whole world, due to the war, and instead of allowing herself to be troubled by fears of a particular rival, she might the better concentrate attention on a reduction in the cost of her goods. She has many powerful allies in this work, allies of real value because they are economic laws not dependent on the caprice of individuals. The fall in the price of wool, the decline now fully evident in the cost of living, and even the fierce competition with which she is faced, will all benefit her. The last-named will benefit her by compelling her captains of industry to overhaul the industries they control, to eliminate waste and extravagance, and to promote efficiency.

It must be remembered that during the war the wool trade in England was protected by what was practically a huge tariff. It was spoon-fed with enormous orders for military uniforms and such like. It had little competition to face and therefore it is not surprising if, like a hot-house plant, a few branches have grown weedy and are likely to be nipped off by the first frost. But the same is true of practically every other country, and what we are experiencing now is but the beginning of a return to more normal and healthy conditions. During such times of transition many innocent people suffer, the more is the pity, and if we ind at the present time there is some disadvantage in laving a good rate of exchange, we must not forget that we are benefiting directly by it in a steady fall in the cost of living and in the cost of most of our raw materials.

When we compare our position with that of a country like Poland or Austria, or Russia, we shall see that we have much to be thankful for. If we find we have much unemployment, it is well to remember that America has three times as much. If we find we are being undercut in certain lines, the remedy is to find out how far the undercutting is of a temporary nature due to the fact that our competitor is harder hit than ourselves in having to sacrifice his goods at a ruinous loss in order to meet current expenses, and how far he may have discovered a more efficient way of producing them. Temporary inequalities, sucl as the rates of exchange, are bound to straighten out. A rate of exchange which is low indicates that that country is not producing enough; therefore, it makes it advantageous for other countries to purchase from 
that country. This naturally increases the demand for the money of the cheap country, whose money rises in proportion. The rates of exchange are only a symptom of the unhealthy conditions of the world as a whole, and I suggest that the soundest method of endeavouring to adjust these difficulties is not to create artificial barriers which will perpetuate them, but to endeavour to lighten the burden of taxation and therefore increase the cousuming power of the various nations and at the same time enable individuals to save part of what they earn so that they can invest it in productive industry. Until this is achieved, we cannot expect conditions to become normal. We do not want another sudden boom, followed by an equally rapid slump; we want a steady revival and development of trade on healthy lines. This, and this only, will restore prosperity. All trade is so closely interlocked that the fact that some countries are on the edge of bankruptcy is quite sufficient to interfere with British export trade. Thus, if Italy cannot afford to buy foodstuffs and raw materials from South America, this will seriously affect the amount of goods South America can purchase from England.

\section{Discussion}

Mr. J. H. Cravien said he should have liked to have heard from Mr. Ward as to where they were going to find trade and how they were going to find trade. In his travels abroad he had been struck with the efforts which the Germans were making to find business. He had also been struck with the fact that many of the travellers sent out from this country could not speak the language and did not know the customs of the country in which they were endeavouring to sell goods, and consequently they failed to get orders. Our young people ought to be taught the language and customs and currencies of the countries with which we wished to trade. With regard to the effect of tariffs, before the war the Huddersfield manufacturers used to sell very largely to Germany and Austria, but the tariff was of no effect because the imported goods were re-exported to other markets and rebates were obtained. Tariff walls did not interfere with that kind of trade. In his opinion, this country would have to pay more attention to the distributive side. He had found that the Germans were quite willing to sell in the currency of the buying country, but that English travellers would only quote in English currency.

Mr. WARD said he should hesitate to recommend firms to sell in the currency of Germany, France or Italy. The fluctuations in exchange were so extensive and rapid that unless he were an expert in exchange the trader would lose.

Mr. G. F. Ashlexy said he had heard of cases in which suits in Germany cost roo marks, representing 8s. 6d. in this country. The importer was selling them at $f_{3}$. With regard to Japanese competition, during the war Canada had imported silks very largely from Japan, and to a great extent they had superseded woollen goods in many uses.

Mr. J. H. CRAVEN asked if Mr. Ward tliought they could cultivate trade abroad by giving longer credits.
Mr. WARD said the Government and the Federation of British Industries were considering a scheme for the giving of long credit, and he thought that scheme would go through. It must be a very big scheme, however; it was no good one manufacturer taking the responsibility on himself. The original scheme failed because the banks would not co-operate. He believed the banks would cooperate in the new scheme, and that it would be a good investment for them. He did not think it was reasonable to propose, as had been done in a recent scheme, that any manufacturer should be entitled to ship to any importer, the Government to take half the risk and the exporter the other half. It was obvious that there were unsound firms in any country, and that the manufacturer or exporter could put his price at such a figure that his 50 per cent. would pay him, whilst if he were paid in full so much the better. In other words, whatever happened he would get the real value of the goods out of the scheme. The actual scheme that was going forward was a very complex one, but had many good features in it, and with regard to certain countries on the Continent it might really be effective in a certain measure. He would like to say, however, that any such scheme must not be regarded as a total solution of the problem. It was a help, because it was facilitating the machinery of banking and merchandising at the present time, and that was very valuable because the Continental banking system had been shattered in many countries. Such a scheme, with adequate guarantees on the part of the country that was going to benefit, would do good; but it was not going to solve the problem of enabling a man with $2 d$. to buy an article that cost $4 \mathrm{~d}$.

The Chuirman (Mr. Geo. Garnett) asked how far gambling in excliange was affecting the present position.

Mr. WARD said that in certain cases there had nndoultedly been a good deal of gambling; for instance, with regard to the German exchange. One could not gamble on a sound exchange, of course. Gambling in exchange, however, he regarded almost as a barometer indicating the soundness or otherwise of the country concerned. To a great extent, also, movements in exchange tended to correct themselves.

Mr. AsHLIEY said that it was interesting to note that the price of cloth was now about $21 / 2$ times that of pre-war times, and as prices generally were on that level, the cloth price seemed reasonable. In pre-war times, however, $60 \%$ of that price was represented by the cost of the manufacturers' raw material, and $40 \%$ by the processes of manufacture; to-day, the cost of raw material represented $30 \%$, and the manufacturers' conversion margin $70 \%$. The cost of weaving, dyeing, and so on was considerably more than $2 \frac{1}{2}$ times pre-war, and it would seem as if these must come down considerably, whilst the raw material might even go up.

Mr. WARD said this opened up a large question, which he could scarcely discuss that evening, but undoubtedly there would have to be certain adjustments in wages scales, and an overhauling of organisation to ensure that maximum efficiency was obtained. 
Sir WILI,IAM WADE, in proposing a vote of thanks to Mr. Ward, said he believed there was no nation in the world to equal Great Britain, and if they pulled together, with mutual sympathy between buyer and seller and employer and employee, he believed they could cope with any difficulty. During these last few years, they had almost lost their heads. It was not a question of selling stuff, but a question of whether they could get it, and if they could, they could sell it. At the present time they could get any quantity of stuff, but could not sell it, or even give it away. That, however, he thought would right itself, if they pulled together and worked together as good friends.

Mr. Culingworth seconded, and the motion was heartily accorded.

\section{LANCASHIRE SECTION.}

Mecting at Manchester, I5th March, I92r.

Mr. T. FleTCHER ROBINSON in the Chair.

\section{THE TECHNOLOGY OF COTTON (CELLULOSE) AND} ITS COMMERCIAL MODIFICATIONS.

By WILLIAM KeNYON.

In the course of this paper, Mr. Kenyon stated that he proposed to endeavour to demonstrate the reasons why the cotton fibre (cellulose) is so valuable an article of commerce and from a technical point of view, by reason of its different properties, both chemical and physical, and, consequently, its capability of becoming chemically and physically changed by the chemical and mechanical processes involved in the various spheres of manufacture.

Apart from the cotton fibre; cellulose obtained from other natural sources forms the basis of manufacture in the artificial silk and paper yarn industries. These industries have been greatly developed during the war and are the outcome of the linking.up of chemistry, biology, and mechanical ingenuity, and we may expect still greater results from the combination having regard to the extended activities in the field of research.

The author dealt in detail with the action of heat on the cotton fibre, and with the chemical composition and properties.

Continuing, he said that the nitro-cellulose and cuprammonium processes for the manufacture of artificial silk are now being gradually displaced by the viscose process-an English process which might be said to owe nothing to German influence. Viscose silk is said to surpass nitro-cellulose and cuprammonium silks in lustre, covering power, dyeing affinity, \&c. Any cellulose may be converted into viscose provided it has been sufficiently purified by removal of ligneous residues and has only been chemically broken down to a slight extent by the purification process. Norwegian wood pulp is usually employed, chiefly owing to price consideration and the convenient form in which it may be used. The wood, generally spruce pine, after removal of the bark, is converted into logs of suitable size. These are cut into large chips by a special machine in order to allow the boiling liquid to penetrate easily. Boiling under pressure takes place in large horizontal boilers, and a solution of calcium-bisulphite removes the resin, \&c., leaving a comparatively pure cellulose. The calcium-bisulphite is then washed out and the pulp is bleached and formed into thick sheets on a paper-making machinc. The sheets of wood pulp are cut to convenient size, steeped in a strong caustic-soda solution of the mercerising strength used for cotton, and then pressed to a constant weight in order to remove the excess of caustic soda and secure a product of uniform composition. The "alkali-cellulose" thus obtained is milled until it is broken up into the form of crumbs, and then treated with carbon bisulphide with which it combines, forming a gelatinous xanthate. This cellular xanthate is at first soluble in water, but as the xanthate groups gradually hydrolyse, giving a product progressively less soluble in water, it is dissolved in dilute caustic soda to keep it in solution. At this stage, all trace of the wood fibre has disappeared, the material having been converted into a perfectly clear, homogeneous, syrup-like liquid ready for the formation of the thread. After careful filtration, the liquid viscose is forced by mechanical pressure through apertures of less than $\mathrm{I} /$ rooth of an inch in diameter. The jets of viscose pass into a liquid which sets them into a firm jelly strong enough to be drawn through the bath and wound up by some convenient form of collector. The bath into which the thread is spun must contain a substance capable of removing the alkaline solvent from the xanthate, and solutions of salts or acids are suitable, a mixture of the two being often employed. In this connection, special apparatus extensively used consists of a rapidly-rotating hollow cylinder, into which the thread is fed by means of a roller, centrifugal force laying the silk evenly on the side of the box and forming an almost solid cake which can be removed for reeling into skeins, the required amount of twist having been imparted by the rotation of the box. The gelatinous thread of cellulose hydrate, after being wound into skeins, is washed until all traces of acid are removed, freed from all chemical impurities, bleached, washed, and dried. It then may be dyed or given any kind of finish or sizing which may be necessary according to requirements.

The production of artificial silk on the Continent is said to be 5 tons daily in Germany, 4 tons in France, and smaller amounts in Belgium, Italy, Switzerland, Austria, and Holland. The industry was making progress in Russia until 1917 , and the latest countries to take up the manufacture are Japan and Sweden. In Great Britain, the output has increased to about ro tons per day, whilst in the United States the output is much greater.

Artificial silk produced commercially from cellulose acetate has been taken up by one firm in this country. It is claimed that the product is specially resistant to moisture. Acetate silk has very low electric conductivity and it may therefore prove to be a most useful material for covering for electric wires and other insulating purposes.

Mr. Knnyon next described the mercerising of cotton and said: Many theories have been advanced on the chemical change which cellulose undergoes in mercerising, but no absolutely definite conclusion has yet been reached. 